\title{
Trails, lanes, or traffic: Valuing bicycle facilities with an adaptive stated preference survey
}

\author{
Nebiyou Y. Tilahun ${ }^{\mathrm{a}, *}$, David M. Levinson ${ }^{\mathrm{b}, 1}$, Kevin J. Krizek ${ }^{\mathrm{c}, 2}$ \\ ${ }^{a}$ Department of Civil Engineering, University of Minnesota, 500 Pillsbury Drive SE, Minneapolis, MN 55455, USA \\ ${ }^{\mathrm{b}}$ Department of Civil Engineering, Director, Networks, Economics and Urban Systems (NEXUS) Research Group, \\ University of Minnesota, 500 Pillsbury Drive SE, Minneapolis, MN 55455, USA \\ ${ }^{\mathrm{c}}$ Urban and Regional Planning Program Director, Active Communities Transportation (ACT), Research Group, \\ University of Minnesota, 301 19th, Ave S., Minneapolis, MN 55455, USA
}

Received 4 April 2005; received in revised form 28 April 2006; accepted 12 September 2006

\begin{abstract}
This study evaluates individual preferences for five different cycling environments by trading off a better facility with a higher travel time against a less attractive facility at a lower travel time. The tradeoff of travel time to amenities of a particular facility informs our understanding of the value attached to different attributes such as bike-lanes, off-road trails, or side-street parking. The facilities considered here are off-road facilities, in-traffic facilities with bike-lane and no on-street parking, in-traffic facilities with a bike-lane and on-street parking, in-traffic facilities with no bike-lane and no on-street parking and in-traffic facilities with no bike-lane but with parking on the side. We find that respondents are willing to travel up to twenty minutes more to switch from an unmarked on-road facility with side parking to an off-road bicycle trail, with smaller changes associated with less dramatic improvements.
\end{abstract}

(c) 2006 Elsevier Ltd. All rights reserved.

Keywords: Bicycling; Stated preference; Adaptive stated preference; Bike-lane; Trail

\section{Introduction}

If bicycling is to be a viable mode of transportation, it must have appropriate facilities. Evaluating what is appropriate requires an understanding of preferences for different types of cycling facilities. In this study we explore and provide a quantitative evaluation of individual preferences for different cycling facility attributes. This understanding can be incorporated into an evaluation of what facilities are warranted for given conditions.

\footnotetext{
* Corresponding author. Tel.: +1 612626 0024; fax: +1 6126267750 .

E-mail addresses: tila0006@umn.edu (N.Y. Tilahun), levin031@umn.edu (D.M. Levinson), kjkrizek@umn.edu (K.J. Krizek).

1 Tel.: +1 612625 6354; fax: +1 6126267750 .

${ }^{2}$ Tel.: +612 625 7318; fax: 6126253513 .
} 
The facilities considered here are: (A) Off-road facilities, (B) In-traffic facilities with bike-lane and no onstreet parking, (C) In-traffic facilities with a bike-lane and on-street parking, (D) In-traffic facilities with no bike-lane and no on-street parking, and (E) In-traffic facilities with no bike-lane but with on-street parking. The aim is to understand what feature people desire by quantifying how many additional minutes of travel they would be willing to expend if these features were to be available. This added travel time is the price that individuals are willing to pay for the perceived safety and comfort the attributes provide.

A computer based adaptive stated preference survey was developed and administered to collect data for this study. To understand if the value that people attach to attributes of facilities is systematically related to different individual and social characteristics, the study has also collected demographic, socioeconomic, household, and current travel mode information from each participant. This information is then used to build an empirical model to evaluate relationships between these independent variables and the additional travel time that people are willing to expend for different attributes of cycling facilities. In addition to giving a measure of the appeal of the attributes under discussion, the model also highlights the social and individual factors that are important to consider in evaluating what facilities to provide.

Interest in studying bicyclists and cycling environments is growing. Recent papers by a number of authors have investigated preferences of cyclists and the bicycling environment as well as the relationship between the supply and use of facilities. Availability of cycling facilities and the type and quality of a cycling facility are important determinants of how well they are used. Studies by Dill and Carr (2003), Nelson and Allen (1997) have shown that there is a positive correlation between the number of facilities that are provided and the percentage of people that use bicycling for commuting purposes. While both studies state that causality cannot be proved from the data, Nelson and Allen (1997) state that in addition to having bicycle facilities, facilities must connect appropriate origins and destinations to encourage cycling as an alternative commuting mode.

Stated Preference has been used to analyze bicycle route choice in the city of Delft. Their work looked at facility type, surface quality, traffic levels and travel time in route choice. Bovy and Bradley's (1985) work found that travel time was the most important factor in route choice followed by surface type. Another study by Hopkinson and Wardman (1996) investigated the demand for cycling facilities using stated preference in a route choice context. They found that individuals were willing to pay a premium to use facilities that are deemed safer. The authors argue that increasing safety is likely more important than reducing travel time to encourage bicycling.

Abraham et al. (2004) also investigated cyclist preferences for different attributes using a SP survey in the context of route choice. Respondents were given three alternate routes and their attributes and were then asked to rank the alternatives. The responses were analyzed using a logit choice model. Among other variables that were of interest to their study, the authors found that cyclists prefer off-street cycling facilities and lowtraffic residential streets. But the authors also claim that this may be due to an incorrect perception of safety on the part of the respondents, and education about the safety of off-road facilities may change the stated choice.

Proximity to an off-road bicycle trail plays in route choice decisions. Using intercept surveys along the Burke-Gilman trail in Seattle, Shafizadeh and Niemeier (1997) find that among people who reported origins near the off-road facility, travel time gradually increases as they are further from trail to a point and then decreases, leading them to speculate that there may be a $0.5-0.75$ mile "bike shed" around an off-road bike path, within which individuals will be willing to increase their travel time to access that facility and outside of which a more direct route seems to be preferred.

Aultman-Hall et al. (1997) use GIS to investigate bicycle commuter routes in Guelph, Canada. While comparing the shortest path to the path actually taken, they found that people diverted very little from the shortest path and that most bicycle commuters use major road routes. They found little use of off-road trails. While this may be due to the location of the trails and the O-D pair they connect, even in five corridors where comparably parallel off-road facilities do exist to in-traffic alternatives, they found that commuters used the intraffic facilities much more often. Only the direct highest quality off-road facility (one that is "wide with a good quality surface and extends long distance with easy access points") seemed to be used relatively more.

Web based stated preference survey's have been used to estimate a logit model to understand important attributes for commuter cyclist route choice. Stinson and Bhat (2003) find that respondents preferred bicycling 
on residential streets to non residential streets, likely because of the low traffic volumes on residential streets. While their model showed that the most important variable in route preference was travel time, the facility was also significant. It was shown that cyclists preferred in-traffic bike-lanes more than off-road facilities. Both facility types had a positive effect on utility but the former added more to utility than the latter. In addition they find that cyclists try to avoid links with on-street parking. Another study by Taylor and Mahmassani (1996) also using a SP survey to investigate bike and ride options, finds that bike-lanes provide greater incentives to inexperienced cyclists (defined as those with a "stated low to moderate comfort levels riding in light traffic") as compared with more experienced cyclists, with the latter group not showing a significant preference to bike-lanes over wide curb lanes.

The results from these papers seem somewhat mixed. Though some of the research has shown a stated preference and revealed preference with some constraints for off-road facilities, others have shown that cyclists generally prefer in-traffic cycling facilities with bike-lanes. Especially in revealed preference cases, the apparent preference for in-traffic routes may be due to their ability to connect to many destinations in a more direct fashion and therefore leading to a lower travel time. In addition route choice may be restricted by facility availability, geographic features or missing information. It may also be that for people who regularly bicycle, who are most likely the subjects of the revealed preference studies, travel time and not perceived safety are likely of utmost importance, as these individuals are more likely to be conditioned to the cycling environment. The actual preference therefore may not be for the in-traffic facility; however, it may be the best alternative available to the cyclists.

Commuter choices are clearly limited by facilities that are available to them. Understanding preferences and behavior is crucial to providing choices that people desire. This can be best accomplished when the value of any given improvement in facility attribute is known. Valuation of facility attributes can be done by considering what people are willing to pay for using these facilities. In this study we try to uncover this value by measuring how much additional time individuals would be willing to spend bicycling between a given origin and destination if alternate facilities with certain attributes were available to them.

In the next section we present the methodology in detail. This is followed by a description of the survey instrument and design. The analysis methodology is presented, and then the results.

\section{Methodology}

The methodology we follow to extract this valuation of attributes uses an adaptive stated preference (ASP) survey. While both revealed and stated preference data can be used to analyze preferences, there are certain advantages to using the latter method in this case. In using consumer revealed preference, often, a limitation arises because only the final consumer choice is observed. This makes it difficult to ascertain how consumers came to their final decision. This complication arises because the number of choices that are available to each consumer may be very large and information on those alternatives that went into an individual's decision may not be fully known. Even in cases where all possible alternatives are known, it is difficult to assess whether the decision makers considered all available alternatives. In addition, the exact tradeoff of interest may not be readily available. Even in cases where the tradeoffs seem to be available, one cannot be certain that the consumer is acting out his preference for the attributes we are observing. The lack of appropriate data can pose a major challenge in this respect.

Stated preference surveys overcome these complications because the experimenter controls the choices. In SP settings, the experimenter determines the choices and the respondent considers. While this may not reflect the actual market choice that individual would make because of the constraints the survey places on the choice set, it allows us to measure attribute differences between the presented alternatives. Further, by using specialized forms of SP such as adaptive stated preference (ASP) one can measure the exact value individuals attach to attributes of interest. In this type of survey each option is presented based on choices the respondent has already made. This allows for the presentation of choices that the individual can actually consider while removing alternatives that the respondent will surely not consider. This methodology has been adopted in a number of contexts, including value of time for commercial vehicle operators (Smalkoski and Levinson, 2005), in mode choice experiments (Bergantino and Bolis, 2002), and in evaluating transit improvements (Falzarno et al., 2000) among others. 


\section{Survey instrument, design and administration}

All respondents of the ASP survey were given nine presentations that compared two facilities at a time. Each presentation asks the respondent to choose between two bicycle facilities. The respondent is told that the trip is a work commute and the respective travel time they would experience for each facility is given. Each facility is presented using a $10 \mathrm{~s}$ video clip taken from the bicyclists' perspective. The clips loop three times and the respondent is able to replay the clip if they wish.

Each facility is compared with all other facilities that are theoretically of lesser quality. For example, an offroad facility (A) is compared with a bike-lane no on-street parking facility (B), a bike-lane with parking facility (C), a no bike-lane no parking facility (D) and a no bike-lane with parking facility (E). Similarly, the four other facilities (B, C, D and E) are each compared with those facilities that are theoretically deemed of a lesser quality. The less attractive of the two facilities is assigned a lower travel time and the alternate (higher quality) path is assigned a higher travel time. The respondent goes through four iterations per presentation with travel time for the more attractive facility being changed according to the previous choice. The first choice set within each presentation assigns the lesser quality facility a $20 \mathrm{~min}$ travel time and the alternate (higher quality) path a $40 \mathrm{~min}$ travel time. Travel time for the higher quality facility increases if the respondent chose that facility and it decreases if the less attractive facility was selected. A bisection algorithm works between 20 and 60 min either raising or lowering the travel time for the alternate path so that it becomes less attractive if it was chosen or more attractive if the shortest path was chosen. By the fourth iteration, the algorithm converges on the
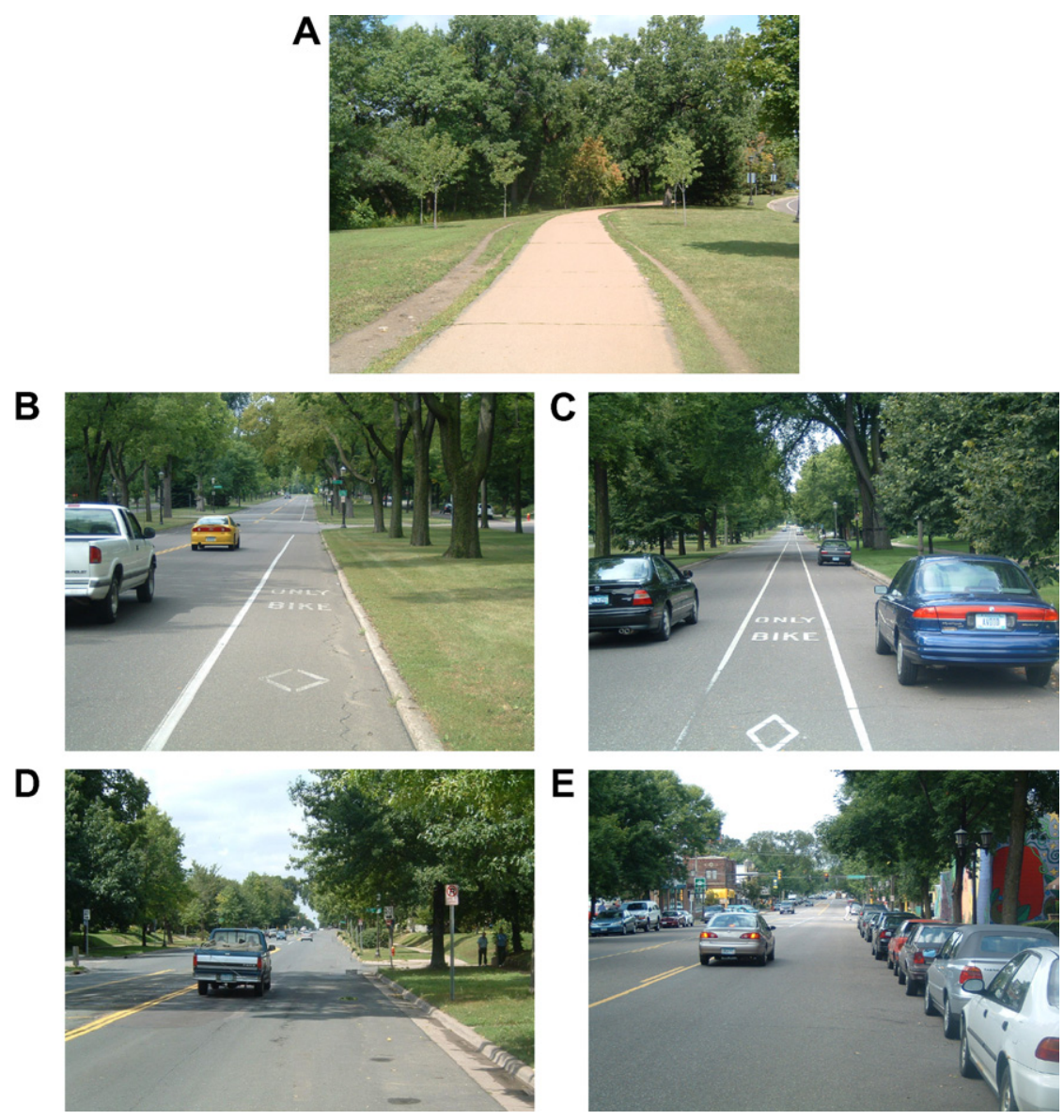

Fig. 1. Cycling facilities used in the study (A) Off-road bicycle facility. (B) Bike-lane, no parking. (C) Bike-lane, on-street parking. (D) Bike-lane, no parking. (E) No bike-lane, on-street parking. 


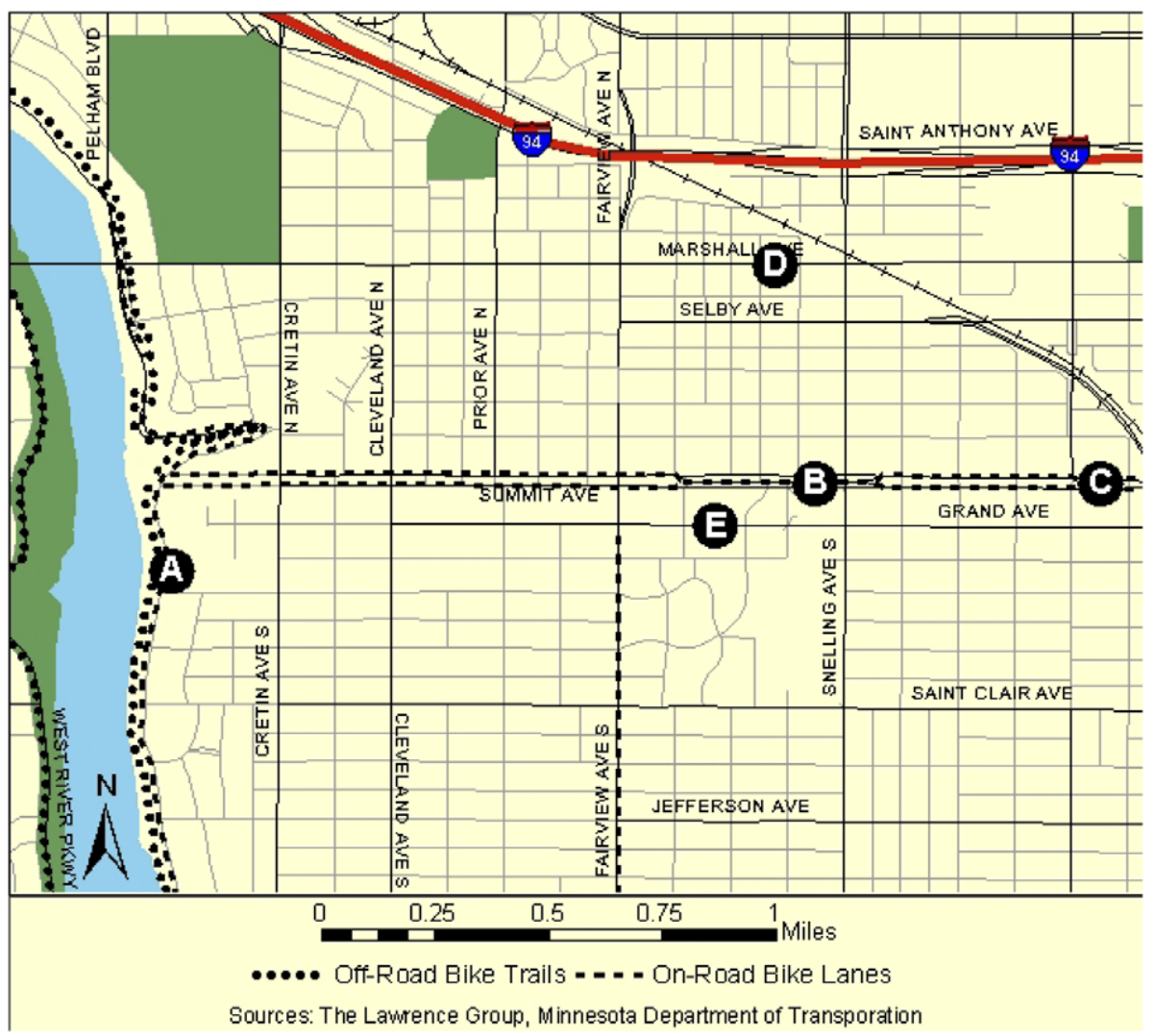

Fig. 2. Location of facilities used in the adaptive stated preference survey Note: (A) off-road facility; (B) bike-lane, no parking facility; (C) a bike-lane, on-street parking facility; (D) a no bike-lane, no parking facility; (E) a no bike-lane, on-street parking facility.

maximum time difference where the respondent will choose the better facility. This way the respondent's time value for a particular bicycling environment can be estimated by identifying the maximum time difference between the two route choices that they will still choose the more attractive facility. Pictures of these facilities are shown on Fig. 1. Fig. 2 maps the locations of the facilities where the videos were taken in St. Paul, Minnesota.

The procedure used to converge on the time trade-off for the particular facility is illustrated as follows. If the subject first chose the longer option, then the next choice set assigns a higher travel time for the higher quality path (raised from $40 \mathrm{~min}$ to $50 \mathrm{~min}$ ). If the respondent still chooses the longer option, the travel time for that choice increases to $55 \mathrm{~min}$ and the choice is posed again. If on the other hand, the 50 min option is

Table 1

Facility pairs compared in the ASP survey

\begin{tabular}{lllll}
\hline Alternate routes & \multicolumn{2}{l}{ Base route } & & \\
\cline { 2 - 5 } & $\begin{array}{l}\text { B Bike-lane, no } \\
\text { parking }\end{array}$ & $\begin{array}{l}\text { C Bike-lane with on-street } \\
\text { parking }\end{array}$ & $\begin{array}{l}\text { D No bike-lane, no } \\
\text { parking }\end{array}$ & $\begin{array}{l}\text { E No bike-lane with } \\
\text { on-street parking }\end{array}$ \\
\hline A off-road & $T_{1}$ & $T_{2}$ & $T_{3}$ & $T_{4}$ \\
B Bike-lane, no parking & N/A & $T_{5}$ & $T_{6}$ & $T_{7}$ \\
$\begin{array}{l}\text { C Bike-lane with on-street } \\
\text { parking }\end{array}$ & N/A & N/A & N/A & $T_{8}$ \\
D No bike-lane, no parking & N/A & N/A & N/A & $T_{9}$ \\
\hline
\end{tabular}

$T_{i}$ represents the average additional travel time user are willing to travel. 
Table 2

Choice order for a sample presentation

\begin{tabular}{llll}
\hline Presentation & Facility travel time & Choice \\
\cline { 2 - 4 } & Route 1 $(\mathrm{min})$ & Route 2 $(\mathrm{min})$ & Route 2 \\
\hline Choice set 1 & 40 & 20 & Route 1 \\
Choice set 2 & 30 & 20 & Route 1 \\
Choice set 3 & 35 & 20 & Route 2 \\
Choice set 4 & 37 & 20 & \\
$T_{i}$ & & 36 & \\
\hline
\end{tabular}

rejected and the respondent chose the 20 min route, the bisection algorithm will calculate a travel time that is between the now rejected option and the previously accepted option, in this case $45 \mathrm{~min}$. By the time the respondent makes a fourth choice, the survey will have either narrowed down the respondents' preference to within two minutes or the respondent has hit the maximum travel time that can be assigned to the longer trip, which is $58.5 \mathrm{~min}$. Table 1 shows the pairs of comparisons that were conducted and used in the analysis. Table 2 shows a sample series of travel time presentations and Fig. $3 \mathrm{a}$ and $\mathrm{b}$ shows sample screenshots of the survey instrument.

The survey was administered in two waves, once during winter and once during summer. The winter and summer respondents were shown video clips that reflected the season at the time of the survey taken at approximately the same location. Our sample for both waves was compromised of employees from the University of Minnesota, excluding students and faculty. Invitations were sent out to 2500 employees, randomly selected from an employee database, indicating that we would like them to participate in a computer based survey about their commute to work and offering \$15 for participation. Participants were asked to come to a central testing station, where the survey was being administered. A total of 90 people participated in the winter survey and another 91 people participated in the summer survey, making a total of 181 people. Among these 13 people had to be removed due to incomplete information leaving 167 people. Of these 167, 68 people indicated that they have bicycled to work at least once in the past year. Thirty eight of these sixty eight identified themselves as regular bicycle commuters at least during the summer. Also, 127 of the 167 people said they have bicycled to somewhere including work in the past year. Further demographic information on the respondents is given in Table 3 .

\section{Model specification and results}

\subsection{Switching point analysis}

The adaptive nature of the survey allows us to extract the actual additional minutes each individual is willing to travel on an alternate facility. In the context of the survey, this is the maximum travel time beyond which the subject would switch to use the lesser quality facility. For each pair of facilities that are compared during the summer and the winter, the averages of this switching point are computed and plotted in Fig. 4. On average, individuals are willing to travel more on an alternate facility when the base facility is $\mathrm{E}$ (undesignated with on-street parking), followed by $\mathrm{D}$ (no bike-lane without parking) and $\mathrm{C}$ (bike-lane with parking). For example individuals are willing to travel further on facility $\mathrm{B}$ when the base facility is $\mathrm{E}$, as opposed to D or C.

Fig. 4 shows the hierarchy between facilities clearly - each of the lines plotted connects the average of the maximum additional travel time that each individual is willing to bicycle over the $20 \mathrm{~min}$ that the base facility would have provided. For example, looking at the winter data, the top solid line connects the average of the maximum additional time individuals say they would travel on an alternate facility when the base facility is $\mathrm{E}$ (in-traffic with parking at $20 \mathrm{~min}$ ). The alternate facilities are as shown on the horizontal axis. For example, looking at the aggregate data, on average subjects are willing to travel about 23 additional minutes if an off-road bike-lane was available if the alternative was to bike in traffic with side parking. We can further 
a

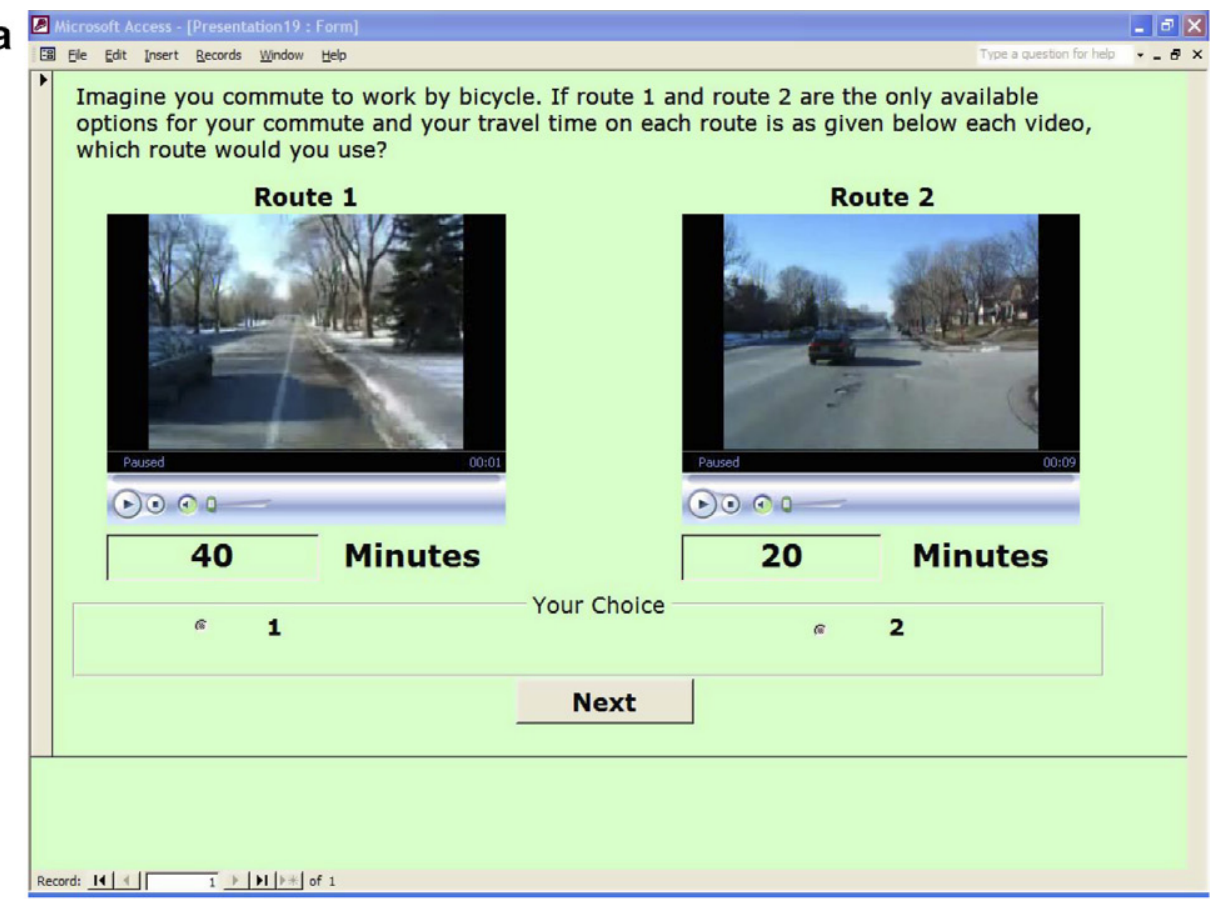

b

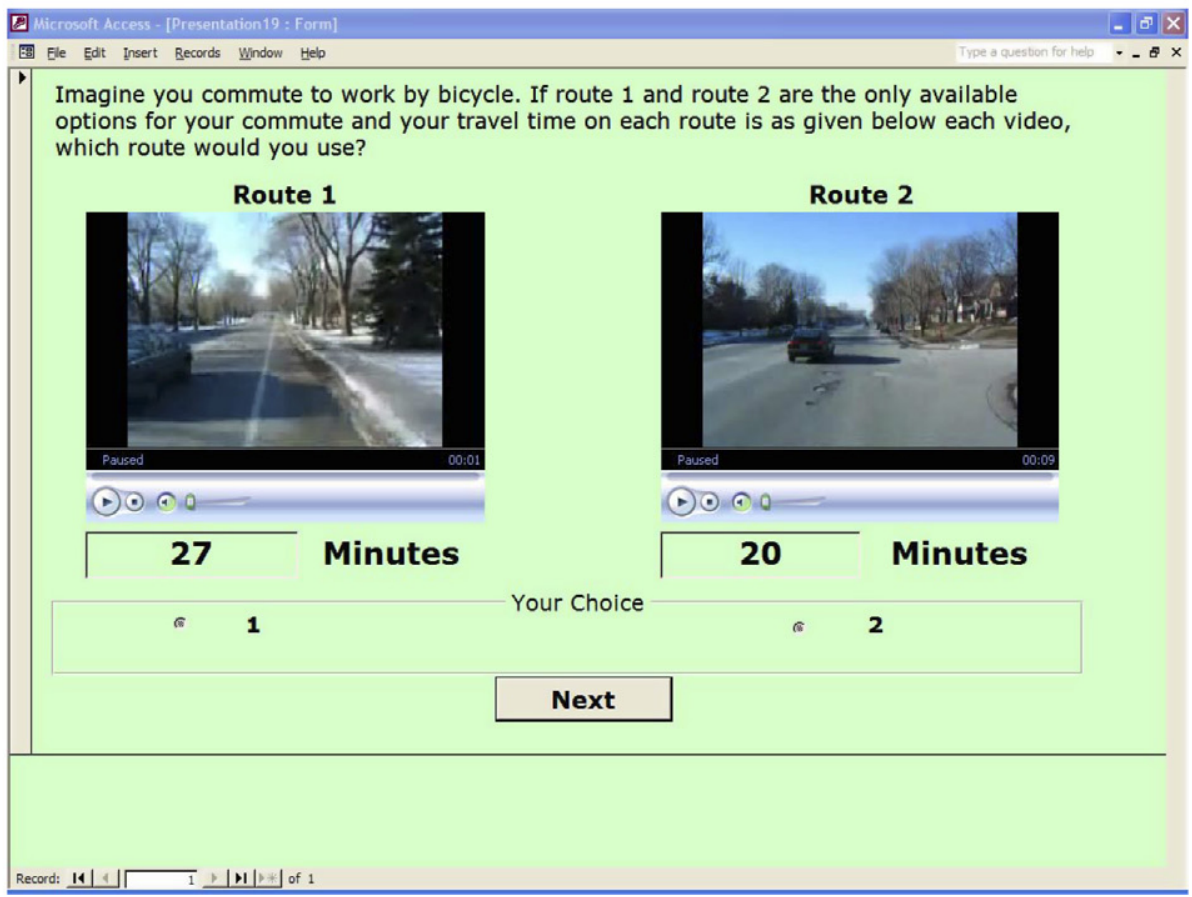

Fig. 3. (a) (top) Comparing designated bicycle lanes with no parking with in-traffic bicycling with no parking and (b) (bottom) Same presentation three iterations later.

approximate the sampling distribution for the mean additional travel time between each pair of facilities by employing methods such as the bootstrap.

The bootstrap, which was first developed by Efron in 1979 (Efron and Tibshirani, 1993), approximates the sampling distribution of the mean by repeatedly sampling with replacement from the original sample and calculating the mean of the resamples. The distribution of the means from the re-sampled data is then 
Table 3

Demographic distribution of respondents

\begin{tabular}{|c|c|c|}
\hline Number of subjects & & 167 \\
\hline \multicolumn{3}{|l|}{ Sex } \\
\hline & $\%$ Male & $34.5 \%$ \\
\hline & $\%$ Female & $65.5 \%$ \\
\hline Age & Mean (Standard deviation) & 44.19 (10.99) \\
\hline \multicolumn{3}{|c|}{ Usual mode (Year round) } \\
\hline & $\%$ Car & $69.7 \%$ \\
\hline & $\%$ Bus & $18.5 \%$ \\
\hline & $\%$ Bike & $9.2 \%$ \\
\hline & $\%$ Walk & $2.6 \%$ \\
\hline \multicolumn{3}{|l|}{ Bike commuter } \\
\hline & All season & $9.2 \%$ \\
\hline & Summer & $22.6 \%$ \\
\hline \multicolumn{3}{|l|}{$\mathrm{HH}$ income } \\
\hline & $<\$ 30,000$ & $8.3 \%$ \\
\hline & $\$ 30,000-\$ 45,000$ & $14.3 \%$ \\
\hline & $\$ 45,000-\$ 60,000$ & $19.6 \%$ \\
\hline & $\$ 60,000-\$ 75,000$ & $15.5 \%$ \\
\hline & $\$ 75,000-\$ 100,000$ & $20.2 \%$ \\
\hline & $\$ 100,000-\$ 150,000$ & $17.9 \%$ \\
\hline & $>\$ 150,000$ & $4.2 \%$ \\
\hline \multicolumn{3}{|l|}{ HH Size } \\
\hline & 1 & $25.0 \%$ \\
\hline & 2 & $32.7 \%$ \\
\hline & 3 & $16.7 \%$ \\
\hline & 4 & $20.8 \%$ \\
\hline & $>4$ & $4.8 \%$ \\
\hline
\end{tabular}

used to estimate a new mean and to approximate the variability of this estimated mean about the true mean. Here we employ the non-parametric bootstrap, which makes no prior assumptions on the distribution of the statistic. Once the resamples are made, and the means are calculated, one can build a confidence interval around the point estimate using the 95 percentiles of the calculated means or using a normal approximation if it is deemed appropriate based on the observed distribution of the bootstrapped mean. The bootstrap analysis is implemented in $R$ using the boot library ( $\mathrm{R}$ Development Core Team, 2004).

Consider the histogram shown in Fig. 5a, it reflects the maximum additional travel time individuals are willing to give for facility A (an off-road trail) if their alternative was facility $\mathrm{C}$ (an in traffic facility with a bike lane and parking). Employing the non-parametric bootstrap on this data with 5000 resamples, with each resample having 167 elements, we can see that the bootstrap distribution of the mean is very close to normal (Fig. 5b). The bootstrap distributions of all nine pairs of comparisons lead to symmetric distributions that show no evidence of non-normality. The percentile confidence interval based on the actual $2.5 \%$ and $97.5 \%$ values of the bootstrapped mean, as well as a normal $95 \%$ confidence interval are computed for each pair of comparisons. From Table 4, it can be seen that the 95\% normal interval and the ordered 95 percentile around the mean are almost the same.

The bootstrap also allows us to estimate the bias of the sample mean by the difference of the mean from the original sample and the bootstrap mean. For each pair of comparisons, the bias in the mean is also found to be very small, being consistently less than $3 / 100$ th of a minute. The sample mean, the estimate of the bias and the confidence interval $(\mathrm{CI})$ using the normal distribution and the percentile of the bootstrap are reported in Table 4 for each pair of comparisons both for the combined and season specific data.

\subsection{Model specification}

We start with the economic paradigm of a utility maximizing individual, where given a bundle of goods the individual chooses that bundle which results in the highest possible utility from the choice set. In the current 

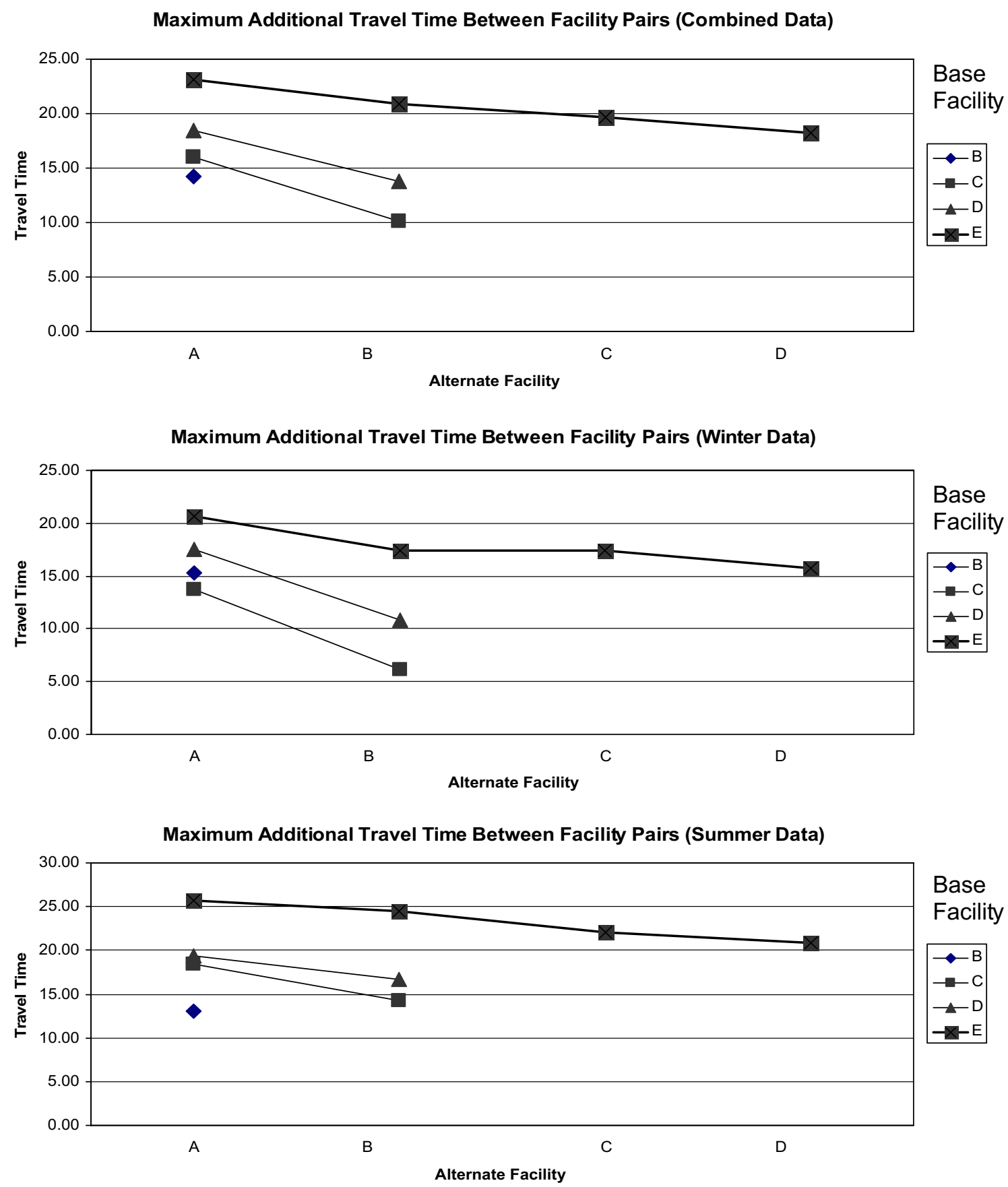

Fig. 4. Hierarchy of Facilities. Note: (A) off-road facility; (B) bike-lane, no parking facility; (C) a bike-lane, on-street parking facility; (D) a no bike-lane, no parking facility; (E) a no bike-lane, on-street parking facility.

context then, given two alternatives $A$ and $B$, the chosen alternative is the one that the subject derives a higher utility from. We can then break down each bundled alternative to its components to understand what amount each contributes to utility. This will enable us to extract the contribution of each feature of the facility in the choice consideration of the individual. Mathematically, we would state this as alternative $A$ is selected if $U_{A}$ is greater than $U_{B}$, where $A$ and $B$ are the alternatives and $U$ is the utility function. 

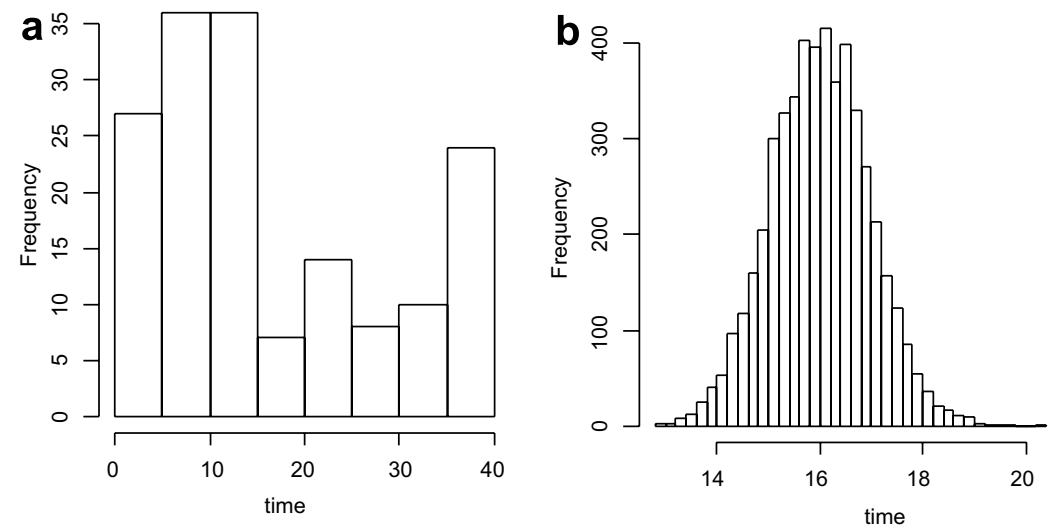

Fig. 5. (a) Distribution of the additional travel time for facility C over facility A and (b) The bootstrapped mean for the additional travel time between facilities $\mathrm{A}$ and $\mathrm{C}$ (based on 5000 resamples).

Table 4

Mean additional travel time between facility pairs and confidence interval of the bootstrapped distribution of the mean

\begin{tabular}{|c|c|c|c|c|c|c|}
\hline Fac 1 & Fac 2 & Original mean & Bias & Standard error & Normal 95\% CI & Percentile $95 \%$ \\
\hline \multicolumn{7}{|c|}{ Combined data } \\
\hline A & $\mathrm{B}$ & 14.21 & 0.0223 & 0.962 & $(12.30,16.08)$ & $(12.41,16.17)$ \\
\hline A & $\mathrm{C}$ & 16.00 & 0.0136 & 0.964 & $(14.10,17.88)$ & $(14.16,17.92)$ \\
\hline A & $\mathrm{D}$ & 18.46 & -0.0160 & 0.984 & $(16.55,20.41)$ & $(16.58,20.40)$ \\
\hline A & $\mathrm{E}$ & 23.14 & -0.0051 & 0.939 & $(21.30,24.98)$ & $(21.26,24.94)$ \\
\hline B & $\mathrm{C}$ & 10.13 & 0.0092 & 0.973 & $(8.21,12.03)$ & $(8.25,12.06)$ \\
\hline B & $\mathrm{D}$ & 13.73 & -0.0008 & 0.957 & $(11.85,15.61)$ & $(11.90,15.62)$ \\
\hline B & $\mathrm{E}$ & 20.87 & 0.0245 & 0.956 & $(18.97,22.72)$ & $(19.09,22.84)$ \\
\hline $\mathrm{C}$ & $\mathrm{E}$ & 19.65 & -0.0033 & 0.950 & $(17.79,21.51)$ & $(17.79,21.49)$ \\
\hline $\mathrm{D}$ & $\mathrm{E}$ & 18.25 & 0.0211 & 1.002 & $(16.27,20.20)$ & $(16.35,20.22)$ \\
\hline
\end{tabular}

Winter data

$\begin{array}{llrrr}\text { A } & \text { B } & 15.33 & 0.0208 & 1.335 \\ \text { A } & \text { C } & 13.69 & 0.0339 & 1.327 \\ \text { A } & \text { D } & 17.57 & -0.0252 & 1.344 \\ \text { A } & \text { E } & 20.66 & -0.0025 & 1.319 \\ \text { B } & \text { C } & 6.17 & -0.0064 & 1.197 \\ \text { B } & \text { D } & 10.86 & -0.0244 & 1.180 \\ \text { B } & \text { E } & 17.45 & -0.0101 & 1.248 \\ \text { C } & \text { E } & 17.39 & -0.0097 & 1.264 \\ \text { D } & \text { E } & 15.72 & 0.0074 & 1.270\end{array}$

$(12.69,17.92)$

$(11.06,16.26)$

$(14.96,20.23)$

$(18.08,23.25)$

$(3.83,8.52)$

(8.57, 13.19)

$(15.02,19.91)$

(14.92, 19.87)

$(13.22,18.20)$

$\begin{array}{rr}-0.0051 & 1.338 \\ 0.0146 & 1.353 \\ 0.0079 & 1.434 \\ -0.0071 & 1.292 \\ 0.0154 & 1.397 \\ -0.0128 & 1.481 \\ -0.0072 & 1.332 \\ 0.0013 & 1.403 \\ -0.0055 & 1.485\end{array}$

$(10.43,15.67)$

$(15.76,21.07)$

$(16.58,22.20)$

(23.21, 28.27)

$(11.53,17.01)$

$(13.86,19.66)$

$(21.85,27.07)$

$(19.27,24.77)$

$(18.01,23.83)$
$(12.78,18.00)$

$(11.21,16.40)$

$(14.99,20.19)$

$(18.16,23.28)$

$(3.97,8.57)$

$(8.58,13.25)$

$(15.02,19.91)$

$(14.98,19.92)$

$(13.22,18.22)$

Summer data

$\begin{array}{lll}\text { A } & \text { B } & 13.04 \\ \text { A } & \text { C } & 18.43 \\ \text { A } & \text { D } & 19.40 \\ \text { A } & \text { E } & 25.73 \\ \text { B } & \text { C } & 14.28 \\ \text { B } & \text { D } & 16.75 \\ \text { B } & \text { E } & 24.46 \\ \text { C } & \text { E } & 22.03 \\ \text { D } & \text { E } & 20.92\end{array}$

We hypothesize that the utility a user derives from using a bicycle facility depends on the features of the facility and the expected travel time on the facility. Choices are also affected by individual characteristics that 
we may not directly observe, but can try to estimate using individual specific variables such as income, sex, age, etc. As discussed earlier, each individual records a response over various alternatives and therefore the data reflects the repeated choices over the same subject. This implies that the errors are no longer independently distributed. To overcome this problem, we can specify a generalized linear mixed model (GLMM) that addresses the 'within subject' and 'between subject' errors separately (Agresti, 2002). These models take the repeated nature of the responses into consideration, and account for differences between individuals that reflect taste heterogeneity. In addition to separating the within subject and between subject errors, using GLMM ensures that the correct error terms are estimated for hypothesis tests. The data analysis for this section is done using SAS/PROC NLMIXED software (SAS Institute, 2004).

The specification for the mixed logit model is as follows. If we let $Y_{i j}$ be the response of individual $i$ on choice $j$, and $b_{i}$ be the random term associated with individual $i$, then for each choice presentation, we can write:

$$
\begin{aligned}
& \left(Y_{i j} / b_{i}\right) \sim \operatorname{binomial}\left(1, p_{i j}\right) \\
& \operatorname{logit}\left(p_{i j}\right)=U_{i j}+b_{i} \\
& b_{i} \sim N\left(0, \sigma^{2}\right)
\end{aligned}
$$

where $U$ is the linear utility derived from each alternative and based on which the choice is made. The utility of each alternative is defined in terms of the attributes of the facility. In addition, we are also interested in trends that can be explained by individual specific variables. The linear component is then defined as follows:

$$
U=f(\text { Facility, Travel Time, Season, Individual Variables) }
$$

The utility of a particular alternative $j$ for individual $i$ can be written as

$$
\begin{aligned}
& U_{i j}=V_{i j}+\varepsilon_{i j} \\
& V_{i j}=\beta_{0}+\beta_{1} W_{i j}+\beta_{2} O_{i j}+\beta_{3} B_{i j}+\beta_{4} P_{i j}+\beta_{5} T_{i j}+\beta_{6} S_{i}+\beta_{7} A_{i}+\beta_{8} I_{i}+\beta_{9} H_{i}+\beta_{10} C_{i}
\end{aligned}
$$

Where:

$W \quad$ Weather $($ winter $=1$, summer $=0)$

$O \quad$ Dummy indicating whether the facility is off-road $(1=\mathrm{Yes}, 0=\mathrm{No})$

$B \quad$ Dummy indicating whether the facility has a bike-lane $(1=\mathrm{Yes}, 0=\mathrm{No})$

$P \quad$ Dummy indicating whether the facility allows vehicle parking $(1=$ absent, $0=$ present $)$

$T \quad$ Expected travel time on the facility being considered

$S \quad$ Sex $($ Male $=1$, Female $=0)$

A Age

I Median household income for the reported income range (Inc/1000)

$H \quad$ Dummy for household Size (hhsize $>2=1$, Otherwise $=0$ )

$C \quad$ Cyclist at least during summer (Yes $=1, \mathrm{No}=0$ )

$\varepsilon \quad$ Gumbel $(0, \lambda)$

To interpret the model appropriately it is important to note how the dummy variables are coded (Table 5). Variable $B$ represents whether a facility has a designated bike-lane, $O$ represents whether the facility is offroad, and $P$ represents whether a facility has no parking adjacent to it. This would allow separately valuing bike-lanes as well as being off-road. It should be observed that ' $O$ ' is not equivalent to an off-road trail. ' $B$ ', ' $O$ ' and ' $P$ ' together constitute an off-road trail.

The parameter estimates of binomial logit model are given in Table 6 . The model is estimated such that the predicted probabilities reflect the odds of choosing the theoretically better facility. The model suggests that there is significant subject-to-subject heterogeneity supporting the use of a mixed model $(\sigma=1.27$, CI (1.10, 1.44)). The signs of the estimated parameters are as expected. The travel time is negative showing an aversion to longer trips. The improvements (off-road, bike-lane and no parking) all have a positive and significant influence on choice of different magnitudes. Of these three, for a given individual, a bike-lane improvement 
Table 5

Coding for facility features

\begin{tabular}{llll}
\hline Facility & $\mathrm{O}$ & $\mathrm{B}$ & $\mathrm{P}$ \\
\hline A (Off-road) & 1 & 1 & 1 \\
B (Bike-lane, No parking) & 0 & 1 & 1 \\
C (Bike-lane, on-street parking) & 0 & 1 & 0 \\
D (In traffic, No parking) & 0 & 0 & 1 \\
E (In traffic, on-street parking) & 0 & 0 & 0 \\
\hline
\end{tabular}

Table 6

Generalized mixed logit model

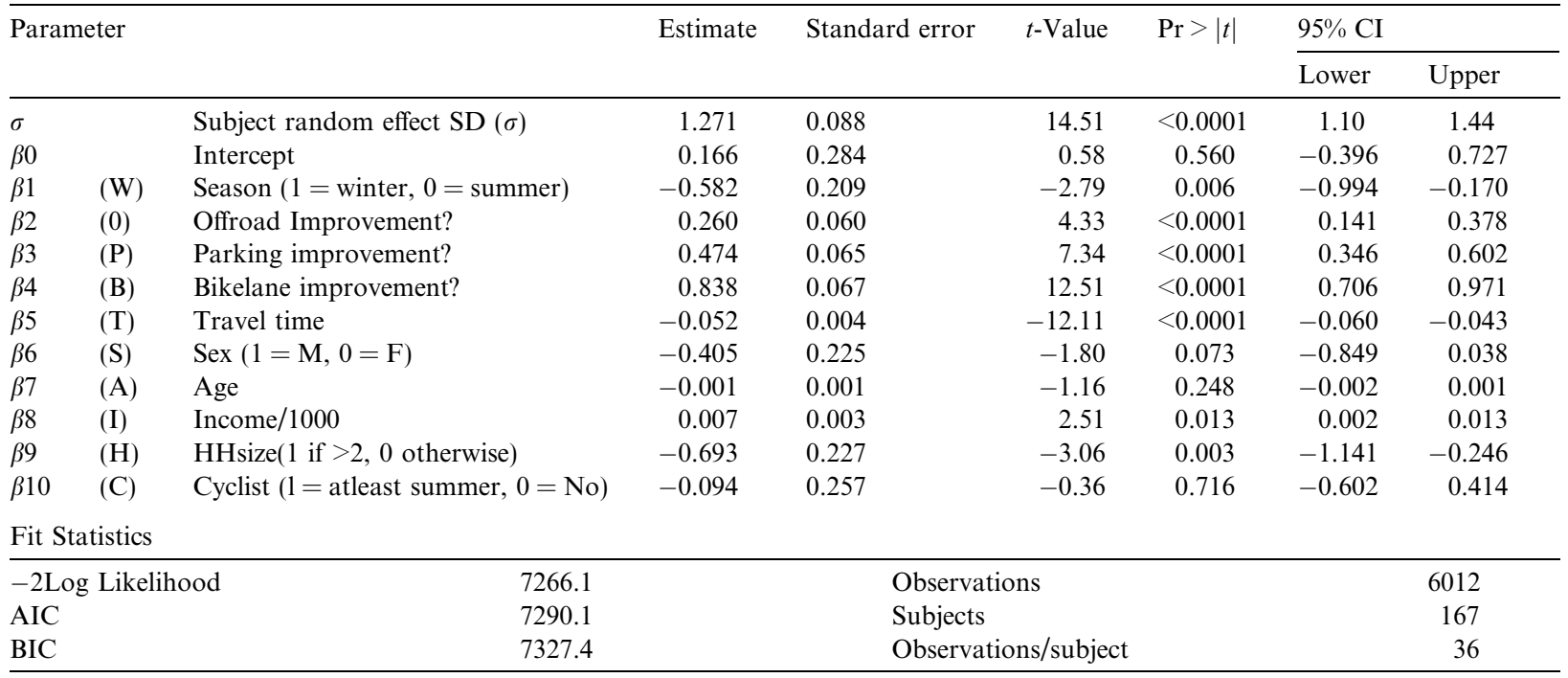

increases the odds of choosing the higher quality path much more than parking elimination or that of an offroad improvement alone.

The season variable is negative and significant, indicating that given all other attributes are held the same, people have lower odds of choosing the better facility during winter than during summer ( $p$-value $=0.006$ ). The model suggests that individuals from higher income households have a higher odds of choosing the better facility given all other variables are held constant ( $p$-value $=0.013$ ). Sex and Age are not significant at the 0.05 level, however the sign for sex indicates that women have a higher tendency to choose the facilities that are perceived safer (better quality) than men $(p$-value $=0.073)$. The cyclist variable, which indicates if the subject uses bicycling as their main mode at least during summer, is highly insignificant; indicating that preferences are not dictated by experience at least in this SP context. Also individuals whose household size is greater than two have lower odds of choosing the better quality, longer travel time facility ( $p$-value $=0.003$ ). This may be because these individuals have higher constraints on their time than individuals who live in single or two person households.

The estimated logit model based on utility theory can be used to determine the time value of a facility being off-road, a bike-lane improvement or the removal of parking. These are derived using the marginal rate of substitution between each of the facility features and travel time. These values are derived based on SP questions that have a $20 \mathrm{~min}$ base travel time, and should be interpreted as such. Accordingly, a bike-lane improvement is valued at 16.41 (CI $(13.25,19.56))$ minutes, a no parking improvement is valued at 9.27 (CI (6.59, $11.94)$ ) minutes and an off-road improvement is valued at 5.13 (CI $(2.76,7.49))$ minutes. This is to say, for a given individual, keeping utility at the same level, one can exchange the off-road improvement for 5.13 minutes of travel time, a bike-lane for $16.41 \mathrm{~min}$ of travel time and a no parking improvement for $9.27 \mathrm{~min}$ of travel time. This says that the most value is attached to having a designated bike lane. While having an 
Table 7

Time values of facility attributes

\begin{tabular}{|c|c|c|c|c|c|c|c|c|}
\hline \multicolumn{2}{|c|}{ Attribute } & \multirow[t]{2}{*}{ Calculated } & \multirow[t]{2}{*}{ Estimate } & \multirow[t]{2}{*}{ Standard error } & \multirow[t]{2}{*}{$t$-Value } & \multirow[t]{2}{*}{$\operatorname{Pr}>|t|$} & \multicolumn{2}{|c|}{$95 \% \mathrm{CI}$} \\
\hline & & & & & & & Lower & Upper \\
\hline $\mathrm{O}$ & Offstreet & $-\beta 2 / \beta 5$ & 5.13 & 1.20 & 4.27 & $<0.0001$ & 2.76 & 7.49 \\
\hline $\mathrm{P}$ & Parking improvement & $-\beta 3 / \beta 5$ & 9.27 & 1.36 & 6.83 & $<0.0001$ & 6.59 & 11.94 \\
\hline B & Bikelane improvement & $-\beta 4 / \beta 5$ & 16.41 & 1.60 & 10.27 & $<0.0001$ & 13.25 & 19.56 \\
\hline
\end{tabular}

off-road facility would certainly increase the utility of the individual, most of the gains of an off-road facility seem to be derived from the fact that such facilities provide a designated bike lane. The absence of parking is also valued more than taking the facility off-road Table 7.

\subsection{Switching point analysis}

An alternate specification of the model looks at time as a dependent variable, and features of the facility as independent variables along with demographic covariates. The dependent variable is the maximum additional minutes individuals would be willing to travel for attributes of an alternate facility. This is the switching point beyond which individuals would take the lesser quality facility. This specification employs a linear mixed models approach to account for the repeated measurements taken over the same subject as was done in the binomial logit case. This approach yields similar patterns in the order of valuation of the different attributes of the facilities and the expected directions of the parameter estimates. The results of this model are reported in Table 8.

\subsection{Comparison}

A side by side comparison of the logit and linear models is not possible; however, we can compare the values derived for different facility pairs based on the logit model and the linear model for a given individual. This is given in Table 9 and Fig. 6. As can be seen from Table 9, most comparisons have confidence intervals that overlap, however the estimates from the logit model are more narrowly estimated as compared to the linear model. In addition, the logit model confidence intervals as well as point estimates closely approximate what is observed in the row data. For instance, between facilities A and D, the logit model estimates a 21.5 min (CI $(17.1,25.9))$ value while the mean from the raw data is 19.4 min $(\mathrm{CI}(16.6,22.2))$.

Table 8

Linear model

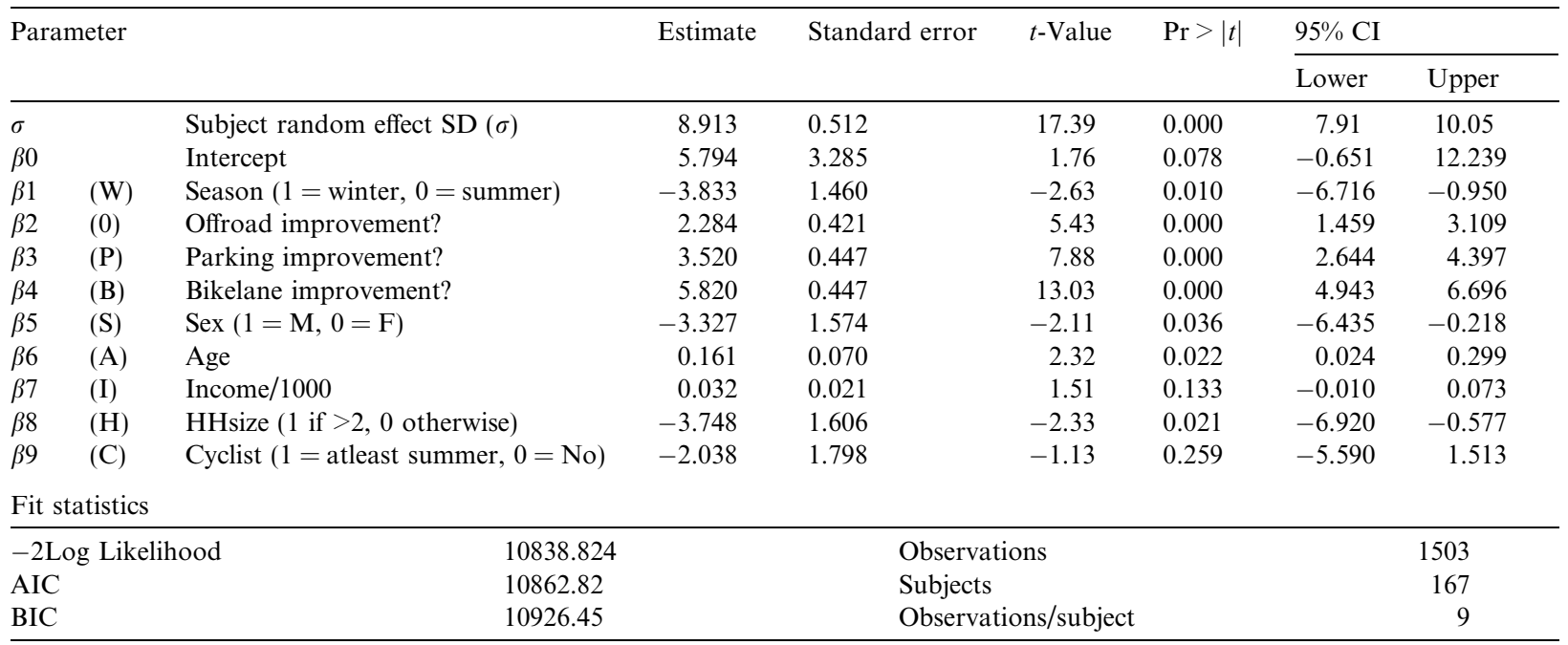


Table 9

Comparison of travel time values between facilities using the linear model and the logit model

\begin{tabular}{lcccccc}
\hline $\begin{array}{l}\text { Facilities } \\
\text { compared }\end{array}$ & $\begin{array}{l}\text { Logit } \\
\text { model }\end{array}$ & $\begin{array}{l}\text { Logit model } \\
\text { CI }\end{array}$ & $\begin{array}{l}\text { Linear } \\
\text { model }\end{array}$ & Linear model CI & $\begin{array}{l}\text { Mean (aggregate raw } \\
\text { data) }\end{array}$ & $\begin{array}{l}\text { Bootstrap 95\% } \\
\text { Normal CI }\end{array}$ \\
\hline A vs B & 5.1 & $(2.8,7.5)$ & 8.1 & $(1.7,14.6)$ & 13.0 & $(10.4,15.7)$ \\
A vs C & 14.4 & $(10.5,18.3)$ & 11.6 & $(5.2,18.1)$ & 18.4 & $(15.8,21.1)$ \\
A vs D & 21.5 & $(17.1,25.9)$ & 13.9 & $(7.5,20.4)$ & 19.4 & $(16.6,22.2)$ \\
A vs E & 30.8 & $(24.7,36.9)$ & 17.4 & $(11.0,23.9)$ & 25.7 & $(23.2,28.3)$ \\
B vs C & 9.3 & $(6.6,11.9)$ & 9.3 & $(2.9,15.8)$ & 14.3 & $(11.5,17.0)$ \\
B vs D & 16.4 & $(13.3,19.6)$ & 11.6 & $(5.2,18.1)$ & 16.7 & $(13.9,19.7)$ \\
B vs E & 25.7 & $(20.6,30.7)$ & 15.1 & $(8.7,21.6)$ & 24.5 & $(21.9,27.1)$ \\
C vs E & 16.4 & $(13.3,19.6)$ & 11.6 & $(5.2,18.1)$ & 22.0 & $(19.3,24.8)$ \\
D vs E & 9.3 & $(6.6,11.9)$ & 9.3 & $(2.9,15.8)$ & 20.9 & $(18.0,23.8)$ \\
\hline
\end{tabular}

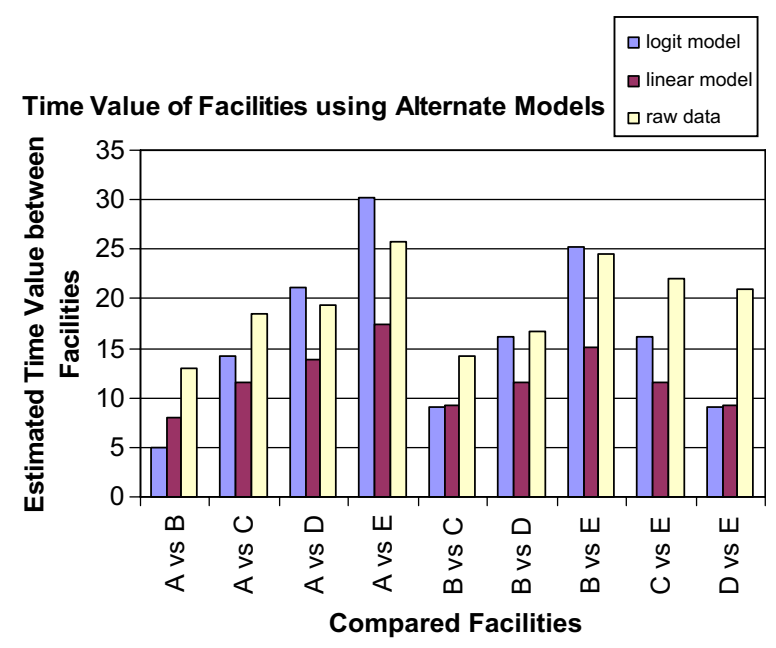

Fig. 6. Comparison of the estimates of the additional time willing to travel between facility pairs based on logit model, linear model and the raw data.

The overall assessment of the models suggests that designated bike lanes seem to be what are most desired. It is also important to consider that both the linear and logit models found no evidence against the hypothesis that preferences between cyclists and non-cyclists are the same. This is encouraging in many respects, because it avoids the dilemma of which interest to serve. The policy implication is that by addressing this common preference, we can ensure cyclists receive the facilities they prefer and non-cyclists get the facilities that they could at least consider as a viable alternative.

\section{Conclusion}

This paper analyzes preferences for different cycling facilities using a computer-based adaptive stated preference survey with first person videos. Using the survey on 167 randomly recruited individuals, we derive the values that users attach to different cycling facility features and expose which are most important. The choice data was collected based on individual preferences between different facilities having different travel times, but the same origin and destination. From the raw data we have demonstrated that a hierarchy exists between the facilities considered and we have extracted a measure of how many additional minutes an individual is willing to expend on an alternate facility if it were available and provided certain features that were not available on the base facility. The data was then used to fit a random parameter logit model using a utility maximizing framework. A linear model was also estimated and compared to the results from the mixed logit model. 
The results show that users are willing to pay the highest price for designated bike-lanes, followed by the absence of parking on the street and by taking a bike-lane facility off-road. In addition, we are able to extract certain individual characteristics that are indicative of preferences such as age, household structure and loose connections with sex and household income. Such an understanding can be incorporated into the planning process to help planners make appropriate recommendations and investment decisions in developing bicycle facilities that are more appealing to the public.

\section{References}

Abraham, J., McMillan, S., Brownlee, A., Hunt, J.D., 2004. Investigation of cycling sensitivities. Presented at 81st Annual Meeting of the Transportation Research Board, Washington, DC.

Agresti, A., 2002. Categorical Data Analysis, second ed. John Wiley \& Sons, Inc., Hoboken, New Jersey.

Aultman-Hall, L., Hall, F., Baetz, B., 1997. Analysis of bicycle commuter routes using geographic information systems: Implications for bicycle planning. Transportation Research Record: Journal of the Transportation Research Board, No, 1578, TRB, National Research Council, Washington, DC., pp. 102-110.

Bergantino, A., Bolis, S., 2002. An adaptive conjoint analysis of freight service alternatives: Evaluating the maritime option. In: IAME 2002 Conference Proceedings, Panama.

Bovy, P., Bradley, P., 1985. Route choice analyzed with stated preference approaches. Transportation Research Record 1037, TRB, National Research Council, Washington, DC.

Dill, J., Carr, T., 2003. Bicycle commuting and facilities in major U.S. cities: If you build them, commuters will use them - another look. CD-ROM. Transportation Research Board, National Research Council, Washington, DC.

Efron, B., Tibshirani, R., 1993. An Introduction to the Bootstrap. Chapman and Hall, New York.

Falzarno, S., Hazlett, R., Adler, T., 2000. Quantifying the value of transit station and access improvements for Chicago's rapid transit system. Presented at 80th Annual Meeting of the Transportation Research Board, Washington, DC.

Hopkinson, P., Wardman, M., 1996. Evaluating the demand for new cycle facilities. Transport Policy 2 (4), $241-249$.

Nelson, A.C., Allen, D., 1997. If you build them, commuters will use them. Transportation Research Record: Journal of the Transportation Research Board, No, 1578, TRB, National Research Council, Washington, DC., pp. 79-83.

R Development Core Team 2004. R: A language and environment for statistical computing. R Foundation for Statistical Computing, Vienna, Austria. ISBN 3-900051-07-0, URL $<$ http://www.R-project.org $>$.

SAS/NLMIXED software, Version 9 of the SAS System for Windows. Copyright (c) 2004 SAS Institute Inc., Cary, NC, USA.

Shafizadeh, K., Niemeier, D., 1997. Bicycle journey-to-work: travel behavior characteristics and spatial attributes. Transportation Research Record: Journal of the Transportation Research Board, No. 1578, TRB, National Research Council, Washington, DC., pp. 84-90.

Smalkoski, B., Levinson, D., 2005. Value of time for commercial vehicle operators. JTRF 44 (1).

Stinson, A.S., Bhat, C.R., 2003. An Analysis of Commuter Bicyclist Route Choice Using a Stated Preference Survey. CD-ROM. Transportation Research Board. National Research Council, Washington, DC.

Taylor, D., Mahmassani, H. 1996. Analysis of stated preference for intermodal bicycle-transit interfaces. In: Transportation Research Record: Journal of the Transportation Research Board, No. 1556, TRB, National Research Council, Washington, DC., pp. 86-95. 